\title{
Effect of airway administration of budesonide for bronchopulmonary dysplasia in premature infants: A Systematic Review and Meta-Analysis
}

kaixu wang

Children's hospital of Chongqing Medical University https://orcid.org/0000-0001-5459-3727

Long Chen

Children's hospital of Chongqing Medical University

Fang Li ( $\sim$ rematalili@163.com )

Research article

Keywords: Budesonide, bronchopulmonary dysplasia, premature infants, meta-analysis, airway administration

Posted Date: November 5th, 2019

DOI: https://doi.org/10.21203/rs.2.16768/v1

License: (c) (1) This work is licensed under a Creative Commons Attribution 4.0 International License.

Read Full License 


\section{Abstract}

Objective: Bronchopulmonary dysplasia (BPD) is one of the major challenges in preterm infants despite the therapeutic improvement. Airway administration of budesonide might be a safe and effective way. However, the optimal timing of airway administration is under determined. The meta-analysis was designed to evaluate the effectiveness and safety of early ( $\leq 1 \mathrm{~d}$ after birth) and late ( $>1 \mathrm{~d}$ after birth) airway administration of budesonide in decreasing the incidence of BPD and death as the primary outcome .

Methods: PubMed, EMBASE, the Cochrane Library, China national knowledge internet (CNKI), China biology medicine disc (CBM), WANFANG data, and China Science and Technology Journal Database were searched for RCTs that compared airway administration of budesonide with controls. The meta-analysis was performed using Review Manager 5.3.

Results: Airway administration of budesonide decreased the risk of BPD at 36 weeks PMA and the composite outcome of BPD or death ( $\mathrm{RR}=0.64,95 \% \mathrm{Cl}$ : $0.55 \sim 0.75$ and $\mathrm{RR}=0.71,95 \% \mathrm{Cl}$ :

0.57 0.89).Moreover, $37 \%$ and $36 \%$ reduction was observed in the incidence of BPD and the composite outcome of BPD or death in the early airway administration group $(\leq 1 \mathrm{~d})(\mathrm{RR}=0.63,95 \% \mathrm{Cl}$ : $0.53 \sim 0.75$ and $\mathrm{RR}=0.64,95 \% \mathrm{Cl}: 0.47 \sim 0.87$ ), while no difference was found in late airway administration group (>1d) $(\mathrm{RR}=0.74,95 \% \mathrm{Cl}: 0.49 \sim 1.13$ and $\mathrm{RR}=0.88,95 \% \mathrm{Cl}: 0.64 \sim 1.21)$.

Conclusion: early airway administration $(\leq 1 d)$ of budesonide reduced the incidence of BPD alone or composite outcome of death or BPD, and it is safe without increasing death as well as other short-term side effects. However, because of the small number of infants in late airway administration group and lacking of long-term follow-up, more randomized controlled trials are needed to testify for the outcomes.

Keywords: Budesonide, bronchopulmonary dysplasia, premature infants, meta-analysis, airway administration.

\section{Background}

Bronchopulmomary dysplasia (BPD) is one of the most common respiratory diseases in premature infants, especially in extremely low birth weight infants [1,2]. The inflammation plays an important mediator of injury in the pathogenesis of BPD $[2,3]$, and corticosteroids are widely used in BPD for its antinflammatory property [4]. Systemic corticosteroid was associated with many adverse short- or long-term outcomes although it significantly reduced the risk of BPD $[5,6]$. Therefore, airway administration of corticosteroids is an effective and safe alternative for fewer side effects [7]. Budesonide is one of optional airway administration of corticosteroids in the Neonatal Intensive Care Unit [8]. Bassler et al. [9] found that inhaled budesonide from $<24$ hours to the infants no longer required oxygen and positivepressure support or they reached 32 weeks PMA couldn't increase the neurodevelopmental disability at 2 years among surviving extremely preterm infants. Several studies with different intervention time demonstrated diverse conclusions of the effect on BPD prevention with local administration of 
corticosteroids [10-12]. As in most RCTs involved, the onset of airway administration of budesonide was within 1 day after birth, our aim was to address the question whether airway administration of budesonide, especially the early onset of intervention ( $\leq 1 \mathrm{~d}$ after birth) could reduce the incidence and improve the outcome of BPD at 36 weeks PMA in premature infants.

\section{Methods}

The studies added to the review must satisfy the following criteria: 1 . Population: Preterm infants (<37weeks); 2. Intervention: Administration of budesonide (or budesonide-surfactant mixture) 3. More than one of the following outcomes: primary outcome of BPD (defined by the need for supplemental oxygen or positive pressure support at 36 weeks PMA) and or death, side effects of infection or sepsis, intraventricular hemorrhage (IVH), and retinopathy of prematurity (ROP); 4.Study design: Randomized controlled trials (RCTs); 5 . Language: Without restrictions. The exclusion criteria: 1 . the definition of BPD was different from this article (defined as requirement of supplemental oxygen at 28 days of life); 2 . Studies existed severe bias based on Cochrane Handbook.

The search strategies were conducted by referring the Cochrane Handbook for Systemic Review of Interventions [13]. A systematic literature search was performed in February 28, 2019, and the databases included PubMed, EMBASE, the Cochrane Library, and Chinese data repositories including China national knowledge internet (CNKI), China biology medicine disc (CBM), WANFANG data, and China Science and Technology Journal Database from their inceptions. The keywords included neonate, infant, newborn, preterm neonate, Preterm infant, premature infant, budesonide, glucocorticoids, corticosteroids, Inhaled corticosteroids, and bronchopulmonary dysplasia. Two reviewers (Wang and Chen) independently identified all abstracts and studies and assessed for inclusion. Full papers were retrieved and inclusion criteria checked by using the Cochrane collaboration tool. We excluded the studies which didn't relate to our topic by reviewing the titles and abstracts, then read the full texts remained to select eligible studies that met our included criteria. We collected data by predesigned forms including the basic characteristics, study design, inclusion criteria, intervening measures, the number of people in the experimental group and control group, and outcomes of the included studies, and we rated the included studies to high risk of bias, low risk of bias, and unclear risk of bias by using the Cochrane collaboration tool [14]. The disagreements we met resolved by discussing with each other.

The data analysis was performed by using version 5.3 of Review Manager. We used Chi-square test $\left(\chi^{2}\right.$ test) and $\mathrm{I}^{2}$ statistics to assess heterogeneity. When the $\mathrm{P}$ value was $>0.1$ or $\mathrm{I}^{2}$ was $\leq 50 \%$ [15], it was considered there was homogeneity between trials. The outcomes of this system review all were dichotomous outcomes, so we used $\mathrm{Z}$ test and risk relative (RR) of $95 \%$ confidence interval (CI) to estimate the treatment effect, and we performed subgroup analysis according to the different intervention time. There were considered statistically significant if the $P$ value was $<0.05$ or the range of value of $95 \%$ $\mathrm{Cl}$ excluded the null. Otherwise, no statistically significant existed.

\section{Results}




\subsection{Study selection.}

We totally identified 720 articles after excluding duplicates and same articles in different databases. However, only 28 articles were potentially satisfied the included criteria by reviewing the titles and abstracts. Finally, 7 eligible articles were included for further analysis [16-22], and 21 articles were excluded for one study without control group, twelve studies with different diagnosis of BPD, and eight studies without sufficient outcomes (Figure1).

\subsection{Characteristics and risk bias of the included studies.}

The summary of 7 RCTs was shown in Tables 1-2 which included the baseline characteristics and details. The 7 RCTS contained a total of 1393 infants, and the publication dates ranged from 1998 to 2017. The Figures 2-3 summarized the quality assessments of these studies. Three studies were deemed to have low risk of bias [19-21], one studies was deemed to have a high risk of bias [18] due to attrition bias, and 4 studies were deemed to have an unclear risk of bias [16-18, 22]. There were 4 studies [19-22] including 1283 infants which of the intervention time were within 1 day after birth and the intervention time of 3 studies [16-18] was at the $3^{\text {rd }}$ and $7^{\text {th }}$ day after birth with 110 infants included.

\subsection{Primary outcomes.}

All included studies recorded the incidence of BPD and death. Airway administration of budesonide decreased the incidence of BPD and the composite outcome of BPD or death $(\mathrm{RR}=0.64,95 \% \mathrm{Cl}$ : $0.55 \sim 0.75$, and $\mathrm{RR}=0.71,95 \% \mathrm{Cl}: 0.57 \sim 0.89)$. To evaluate the intervention timing, we classified the participants to two subgroups: early airway administration ( $\leq 1 \mathrm{~d}$ ) [19-22] (subgroup1) and late airway administration (>1d) [16-18] (subgroup2). Early airway administration showed a reduction in the incidence of BPD and the risk of mortality or BPD (RR $=0.63,95 \% \mathrm{Cl}: 0.53 \sim 0.75$ and $\mathrm{RR}=0.64,95 \% \mathrm{Cl}$ : $0.47 \sim 0.87)$. With respect to the late airway administration ( $>1 \mathrm{~d})$, there was no statistical significance in reduction in incidence of BPD and the risk of mortality or BPD $(\mathrm{RR}=0.74,95 \% \mathrm{Cl}: 0.49 \sim 1.13$ and $\mathrm{RR}=$ 0.88, 95\% Cl: 0.64 1.21) (Figure 4 and Figure5). Compared with control group, no significant differences in mortality were recorded in budesonide group ( $R R=0.94,95 \% \mathrm{Cl}: 0.60 \sim 1.47)$, early airway administration ( $R R=0.86,95 \% \mathrm{Cl}: 0.51 \sim 1.44)$ and late airway administration $(\mathrm{RR}=1.60,95 \% \mathrm{Cl}$ : 0.59 4.33) (Figure6).

\subsection{Secondary outcomes.}

As for the side-effect events, we mainly recorded the incidence of infection (or sepsis), IVH, and ROP. All studies recorded the incidence of infection (or sepsis). One study [17] didn't report the rate of IVH and two studies $[17,18]$ lack of recording the incidence of ROP. No significant differences were found in the sideeffect events of the 7 RCTS (Table3-5).

\section{Discussion}


7 RCTs [16-22] were involved in this meta-analysis, our aim was to evaluate the effectiveness and safety of airway administration of budesonide for BPD and try to assess optimal intervention time. In accord with previous meta-analysis, airway administration of budesonide was recorded to reduce the incidence of BPD in our study. Furthermore, we found that early airway administration of budesonide ( $\leq 1$ day) was associated with a decreased risk of BPD in preterm infants without increasing death, infection or sepsis, IVH, and ROP. Early airway administration of budesonide can also prevent BPD or death, but significant heterogeneities were found between trials which might be due to the different ways for budesonide administration. Among them, budesonide was instilled through trachea in 3 studies [19, 21, 22], and in the rest of studies [16-18,20], budesonide was inhaled with nebulizer. And Yi-jiang Chen et al. [23] demonstrated that instillation budesonide might be better than inhalation by meta-analysis.

Inflammation is one of the key pathophysiologic mechanisms of BPD [2, 3, 24], and Proinflammatory cytokines are important mediators in the early inflammatory response [25]. Immature lung of premature infant was vulnerable to prenatal and early postnatal infections, hyperoxia, and mechanical ventilation which would cause a proinflammatory response and lead to complex inflammatory response and pulmonary alveoli reconstruction $[24,25]$. Antenatal infections and early postnatal systemic inflammation contributed to BPD pathogenesis $[26,27]$. Budesonide is a potentially effective and safe therapy for prevention BPD delivered by Inhalation and instillation $[8,9,28]$.

However, the appropriate intervention time about the airway administration of budesonide for prevention of BPD still remains controversial at present. Cole et al. [12] suggested that early inhaled beclomethasone between 3 to 14 days failed to prevent BPD. Two recent meta-analysis $[10,11]$ have analyzed the effectiveness of inhaled corticosteroids for prevention BPD at different timepoint with different conclusions. Onland $W$ et al. [10] found late inhalation corticosteroids after 7 days of life didn't prevent the BPD, while Shah et al. [11] found inhaled corticosteroids reduced the incidence of BPD earlier than 2 weeks of life significantly. The different intervention time and the lack of subgroup analysis as we performed attenuated the accuracy and effectiveness of those studies. Therefore, it is necessary to compare the efficacy of early and late airway administration of corticosteroids classified by a certain timepoint. Moreover, multiple corticosteroids involved may complicate their results. In our meta-analysis, the intervention time ranged from 1 to 7 days after birth in 7 RCTs. The pulmonary inflammatory response starts very early after birth and may appear prenatally in preterm infants with BPD [29, 30]. Aghai et al. found histological chorioamnionitis was associated with increased proinflammatory mediators within 48 hours after birth [31]. Yeh et al. [32] and Soll et al. [33] found early ( $\leq 1 d)$ use of systemic postnatal corticosteroids, as compared with control group, could reduce BPD and didn't increase death. Therefore, we set 1 day after birth to differentiate "early" and "late" airway administration of corticosteroids. As for the strong local anti-inflammatory property of budesonide [34], our meta-analysis focuses on reviewing the effectiveness and safety of budesonide. In our review, we find that airway use of budesonide can prevent BPD at 36 weeks PMA. What's more, the subgroup analysis shows early $(\leq 1 \mathrm{~d})$ airway administration of budesonide decreased BPD remarkably. However, late ( $>1 d)$ use of budesonide failed to reduce BPD significantly. Our positive finding might due to the early anti-inflammation property of budesonide. It tended to decrease the number of inflammatory cells, promote endogenous SP-B 
synthesis and secretion which help to reduce alveolar surface tension, and promote alveoli development [34]. Moreover, budesonide can restrain chemokine mRNA synthesis and degrade previously secreted chemokine, and after use, the budesonide repression began by 4 hours with high potency and slow reversibility $[35,36]$. Therefore, earlier airway administration of budesonide might be preferred to reduce lung injury and BPD. AS for the late intervention time of included studies in our meta-analysis is at the $3^{\text {rd }}$ and $7^{\text {th }}$ day after birth, we draw a similar conclusion with Onland $W$ et al. [10], but this conclusion should be interpreted with caution because the number of infants is small.

As for the adverse effects, our meta-analysis shows that airway administration of budesonide is safe because it doesn't increase the risk of short-term side effects including death, infection or sepsis, IVH, and ROP which is similar to Shiwell E.S et al. [28] and Zhang Z.Q et al [37]. Our meta-analysis lacks of recording long-term side effects about the budesonide. Kelly et al. [38] and Bassler et al. [9] found that inhaled corticosteroids were not associated with neurodevelopmental impairment. However, Bassler et al. [9] found the higher mortality with budesonide in their study at a corrected age of 18 to 22 months (1.37; $95 \%[\mathrm{Cl}], 1.01$ to $1.86 ; \mathrm{P}=0.04)$. And they thought the higher mortality in budesonide group might be unreliable because it was of nominal statistical significance and may have been due to chance. Therefore, inhaled budesonide may be no obvious long-term side effects.

Several limitations in our review which might affect the interpretation of results can be seen as follows. Firstly, small number of late administration group and the late intervention time limited to the $3^{\text {rd }}$ and $7^{\text {th }}$ day after birth might abate accuracy and reliability. Secondly, due to the different definition of BPD, the incidence of BPD ranged from $6 \%$ to $57 \%$ [39]. The definition of BPD in this meta-analysis referred to preterm infants who need oxygen dependence at 36 weeks PMA, therefore, many studies with other definitions of BPD (defined as requirement of supplemental oxygen at 28 days of life) were excluded. Thirdly, in the RCT by Kovacs et al [16], the steroid group received systemic dexamethasone for 3 days followed by nebulized budesonide for 18 days, and it might be debatable whether this trial should have been included in this meta-analysis due to use dexamethasone. It maybe don't make a noticeable difference because Halliday et al [40] found there were no significant differences for the oxygen dependency at 36 weeks PMA or death by comparing dexamethasone with inhaled budesonide in preterm infants. Moreover, the budesonide-delivery ways, dose, duration, frequency and whether to use pulmonary surfactant are also different in trials leading to significant heterogeneities to some of our findings. Finally, the present meta-analysis lacks of recording the long-term side effects, so lots of RCTs are needed to establish the long-term safety.

\section{Conclusions}

In our meta-analysis, early airway administration ( $\leq 1 \mathrm{~d})$ of budesonide reduced the incidence of BPD at 36 weeks PMA and airway administration of budesonide is a safe therapy without increasing death and other side-effect events. However, because of the small number of infants in late airway administration of budesonide and lacking long-term effects, more randomized controlled trials are needed to testify for the outcomes and long-term safety. 


\section{Declarations}

\subsection{Abbreviations}

PMA: Postmenstrual age; BPD: Bronchopulmonary dysplasia; RCTs: Randomized controlled trials; Cl: Confidence interval; IVH: Intraventricular hemorrhage; ROP: Retinopathy of prematurity; CBM: China biology medicine disc; CNKI: China national knowledge internet.

\subsection{Acknowledgements}

Not applicable.

\subsection{Funding}

This work was supported by the National Natural Science Foundation of China (grant number 81401236), the funding source play no role in study design, data collection, data analysis, data interpretation, writing of the report, or in the decision to submit the report for publication.

\subsection{Availability of data and materials}

All data generated or analyzed during this study are included in this published article (and its supplementary information files).

\subsection{Authors' contributions}

Conception and design: Kai-xu Wang, Long Chen, Fang Li; Acquisition of data, analysis and interpretation of data: Kai-xu Wang, Long Chen, Fang Li; Drafting the article: Kai-xu Wang; Revising the article critically for important intellectual content: Kai-xu Wang, Long Chen, Fang Li; Final approval of the version to be published: Kai-xu Wang, Long Chen, Fang Li; Agreed to be accountable for all aspects of the work in ensuring that questions related to the accuracy or integrity of any part of the work are appropriately investigated and resolved: Kai-xu Wang, Long Chen, Fang Li; All of the authors read and approved the manuscript.

\subsection{Ethics approval and consent to participate}

Not applicable.

\subsection{Consent for publication}


Not applicable.

\subsection{Competing interests}

The authors declare that they have no competing interests

\section{References}

1.Niedermaier S, Hilgendorff A: Bronchopulmonary dysplasia - an overview about pathophysiologic concepts. Mol Cell Pediatr 2015, 2(1):2.

2.Bassler D: Inhalation or instillation of steroids for the prevention of bronchopulmonary dysplasia. NEONATOLOGY 2015, 107(4):358-359.

3.Gentner S, Laube M, Uhlig U, Yang Y, Fuchs HW, Dreyhaupt J, Hummler HD, Uhlig S, Thome UH: Inflammatory Mediators in Tracheal Aspirates of Preterm Infants Participating in a Randomized Trial of Permissive Hypercapnia. FRONT PEDIATR 2017, 5.246.

4.Gupta S, Prasanth K, Chen CM, Yeh TF: Postnatal corticosteroids for prevention and treatment of chronic lung disease in the preterm newborn. Int J Pediatr 2012, 2012:315642.

5.Ji FJ, Yin Y, Xu J, Zhao LX, Zhou YJ, Zhu L: [Early postnatal application of glucocorticoids for preventing bronchopulmonary dysplasia in preterm infants: a Meta analysis]. Zhongguo Dang Dai Er Ke Za Zhi 2017, 19(6):638-645.

6.Zeng L, Tian J, Song F, Li W, Jiang L, Gui G, Zhang Y, Ge L, Shi J, Sun X et al: Corticosteroids for the prevention of bronchopulmonary dysplasia in preterm infants: a network meta-analysis. Arch Dis Child Fetal Neonatal Ed 2018.

7.Lister P, lles R, Shaw B, Ducharme F: Inhaled steroids for neonatal chronic lung disease. Cochrane Database Syst Rev 2000(3):D2311.

8.Ke H, Li ZK, Yu XP, Guo JZ: [Efficacy of different preparations of budesonide combined with pulmonary surfactant in the treatment of neonatal respiratory distress syndrome: a comparative analysis]. Zhongguo Dang Dai Er Ke Za Zhi 2016, 18(5):400-404.

9.Bassler D, Shinwell ES, Hallman M, Jarreau PH, Plavka R, Carnielli V, Meisner C, Engel C, Koch A, Kreutzer K et al: Long-Term Effects of Inhaled Budesonide for Bronchopulmonary Dysplasia. N Engl J Med 2018, 378(2):148-157.

10.Onland W, Offringa M, van Kaam A: Late ( $>$ / = 7 days) inhalation corticosteroids to reduce bronchopulmonary dysplasia in preterm infants. Cochrane Database Syst Rev 2017, 8:D2311. 
11.Shah VS, Ohlsson A, Halliday HL, Dunn M: Early administration of inhaled corticosteroids for preventing chronic lung disease in very low birth weight preterm neonates. Cochrane Database Syst Rev 2017, 1:D1969.

12.Cole CH, Colton T, Shah BL, Abbasi S, MacKinnon BL, Demissie S, Frantz IR: Early inhaled glucocorticoid therapy to prevent bronchopulmonary dysplasia. N Engl J Med 1999, 340(13):1005-1010.

13.Lefebvre C, Eric M, Glanville J: Chapter 6: Searching for studies. In: Higgins JPT, Green S \editors】. Cochrane Handbook for Systematic Reviews of Interventions. Version 5.0.2 [updated September 2009]: The Cochrane Collaboration, 2009. Available from www.cochrane-handbook.org.

14. Higgins JPT ADSJ: Chapter 8: Assessing risk of bias in included studies. In: Higgins JPT, Green S (editors). Cochrane Handbook for Systematic Reviews of Interventions. Version 5.1.0 [updated March 2011]: The Cochrane Collaboration, 2011. Available from www.cochrane-handbook.org.

15.Higgins JP, Thompson SG: Quantifying heterogeneity in a meta-analysis. STAT MED 2002, 21(11):1539-1558.

16.Kovacs L, Davis GM, Faucher D, Papageorgiou A: Efficacy of sequential early systemic and inhaled corticosteroid therapy in the prevention of chronic lung disease of prematurity. ACTA PAEDIATR 1998, 87(7):792-798.

17.Merz U, Kusenbach G, Hausler M, Peschgens T, Hornchen $\mathrm{H}$ : Inhaled budesonide in ventilatordependent preterm infants: a randomized, double-blind pilot study. Biol Neonate 1999, 75(1):46-53.

18.Jonsson B, Eriksson M, Soder O, Broberger U, Lagercrantz H: Budesonide delivered by dosimetric jet nebulization to preterm very low birthweight infants at high risk for development of chronic lung disease. ACTA PAEDIATR 2000, 89(12):1449-1455.

19.Yeh TF, Lin HC, Chang CH, Wu TS, Su BH, Li TC, Pyati S, Tsai CH: Early intratracheal instillation of budesonide using surfactant as a vehicle to prevent chronic lung disease in preterm infants: a pilot study. PEDIATRICS 2008, 121(5):e1310-e1318.

20.Bassler D, Plavka R, Shinwell ES, Hallman M, Jarreau PH, Carnielli V, Van den Anker JN, Meisner C, Engel C, Schwab M et al: Early Inhaled Budesonide for the Prevention of Bronchopulmonary Dysplasia. $N$ Engl J Med 2015, 373(16):1497-1506.

21.Yeh TF, Chen CM, Wu SY, Husan Z, Li TC, Hsieh WS, Tsai CH, Lin HC: Intratracheal Administration of Budesonide/Surfactant to Prevent Bronchopulmonary Dysplasia. Am J Respir Crit Care Med 2016, 193(1):86-95.

22.L-J D, H-B P, X-Q G: Effects of budesonide combined with pulmonary surfactant on bronchopulmonary dysplasia in patients with severe respiratory distress syndrome. Chin J Neonatol 2017, 32(5). 
23.Yi-jiang C, Shui-tang Z, Run-na Y: Intratracheal administration of budesonide within seven days after birth for preventing bronchopulmonary dysplasia in preterm infants $₫$ a systematic review and metaanalysis. Chinese JOurnal of Evidence Based Pediatrics 2016, 11(4):259-264.

24.Niedermaier S HA: Bronchopulmonary dysplasia-an overview about pathophysiologic concepts. Molecular and cellular pediatrics 2015, 2(1):2.

25.Speer CP: Pulmonary inflammation and bronchopulmonary dysplasia. J PERINATOL 2006, 26 Suppl 1:S57-S62, S63-S64.

26.Choi CW, Lee J, Oh JY, Lee SH, Lee HJ, Kim Bl: Protective effect of chorioamnionitis on the development of bronchopulmonary dysplasia triggered by postnatal systemic inflammation in neonatal rats. PEDIATR RES 2016, 79(2):287-294.

27.Rostas SE, McPherson C: Systemic Corticosteroids for the Prevention of Bronchopulmonary Dysplasia: Picking the Right Drug for the Right Baby. Neonatal Netw 2016, 35(4):234-239.

28.Shinwell ES, Portnov I, MeerpohI JJ, Karen T, Bassler D: Inhaled Corticosteroids for Bronchopulmonary Dysplasia: A Meta-analysis. PEDIATRICS 2016, 138(6).

29.Kallapur SG, Jobe AH: Contribution of inflammation to lung injury and development. Arch Dis Child Fetal Neonatal Ed 2006, 91(2):F132-F135.

30. Hayes DJ, Feola DJ, Murphy BS, Shook LA, Ballard HO: Pathogenesis of bronchopulmonary dysplasia. RESPIRATION 2010, 79(5):425-436.

31.Aghai ZH, Camacho J, Saslow JG, Mody K, Eydelman R, Bhat V, Stahl G, Pyon K, Bhandari V: Impact of histological chorioamnionitis on tracheal aspirate cytokines in premature infants. Am J Perinatol 2012, 29(7):567-572.

32.TF Y, YJ L, CH L: The effects of early postnatal dexamethasone therapy on pulmonary outcome in premature infants with respiratory distress syndrome: a two-year follow-up study. ACTA PAEDIATR 2005, 94.310-316.

33.RF S: Early postnatal dexamethasone therapy for the prevention of chronic lung disease. PEDIATR RES $1999,45.226$ A.

34.Li L, Yang C, Feng X, Du Y, Zhang Z, Zhang Y: Effects of intratracheal budesonide during early postnatal life on lung maturity of premature fetal rabbits. Pediatr Pulmonol 2018, 53(1):28-35.

35.Barrette AM, Roberts JK, Chapin C, Egan EA, Segal MR, Oses-Prieto JA, Chand S, Burlingame AL, Ballard PL: Antiinflammatory Effects of Budesonide in Human Fetal Lung. Am J Respir Cell Mol Biol 2016, 55(5):623-632. 
36.Kothe TB, Royse E, Kemp MW, Schmidt AF, Salomone F, Saito M, Usuda H, Watanabe S, Musk GC, Jobe $\mathrm{AH}$ et al: Effects of budesonide and surfactant in preterm, fetal sheep. Am J Physiol Lung Cell Mol Physiol 2018.

37.Zhang ZQ, Zhong Y, Huang XM, Du LZ: Airway administration of corticosteroids for prevention of bronchopulmonary dysplasia in premature infants: a meta-analysis with trial sequential analysis. BMC PULM MED 2017, 17(1):207.

38.Kelly EN, Shah VS, Levenbach J, Vincer M, DaSilva O, Shah PS: Inhaled and systemic steroid exposure and neurodevelopmental outcome of preterm neonates. J Matern Fetal Neonatal Med 2018, 31(20):2665-2672.

39. Hines D, Modi N, Lee SK, Isayama T, Sjors G, Gagliardi L, Lehtonen L, Vento M, Kusuda S, Bassler D et al: Scoping review shows wide variation in the definitions of bronchopulmonary dysplasia in preterm infants and calls for a consensus. ACTA PAEDIATR 2017, 106(3):366-374.

40. Halliday HL, Patterson CC, Halahakoon CW: A multicenter, randomized open study of early corticosteroid treatment (OSECT) in preterm infants with respiratory illness: comparison of early and late treatment and of dexamethasone and inhaled budesonide. PEDIATRICS 2001, 107(2):232-240.

\section{Figures}


English studies(812):PubMed(657),Embase(96),Cochrane Library(59)
Chinese

studies(66):CBM(20),CNKI(14),VIP(11),WanFang(21)

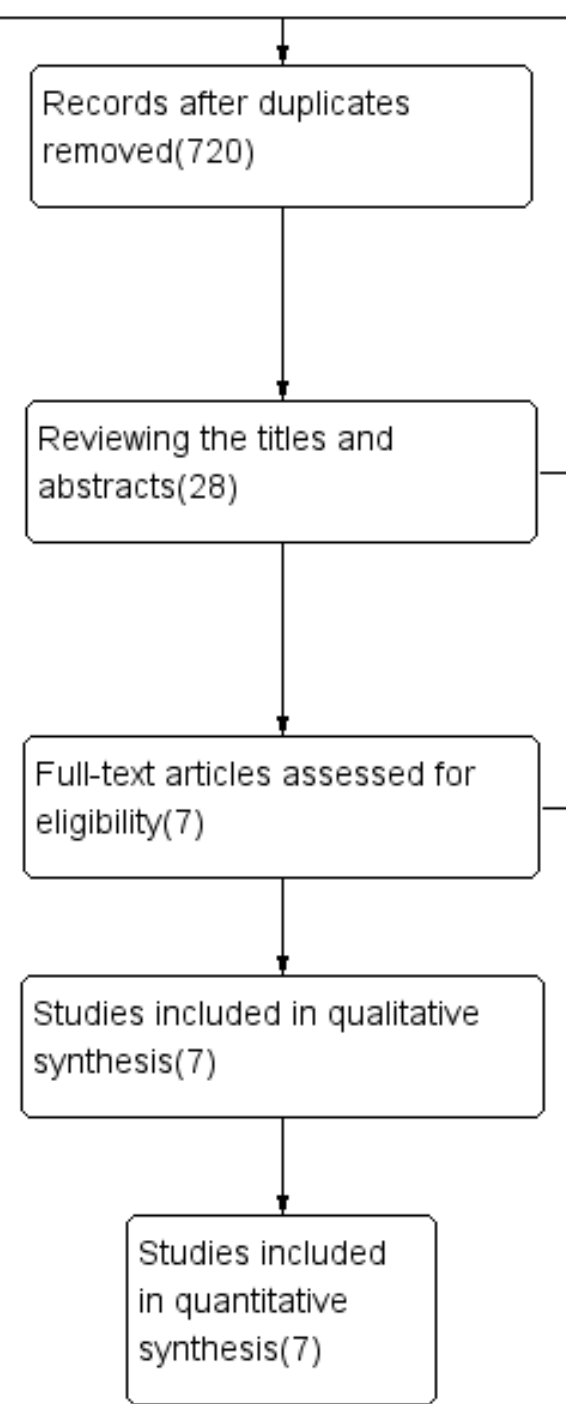

Studies excluded(689): not RCTS, irrelevant themes, not airway administration, not obtainable whole articles
Full-text articles excluded(21): without control group(1), different diagnosis of $\mathrm{BPD}(12)$, insufficient outcomes(8)

\section{Figure 1}

The flow diagram of selecting studies

Random sequence generation (selection bias) Allocation concealment (selection bias)

Blinding of participants and personnel (performance bias)

Blinding of outcome assessment (detection bias)

Incomplete outcome data (attrition bias)

Selective reporting (reporting bias)

Other bias

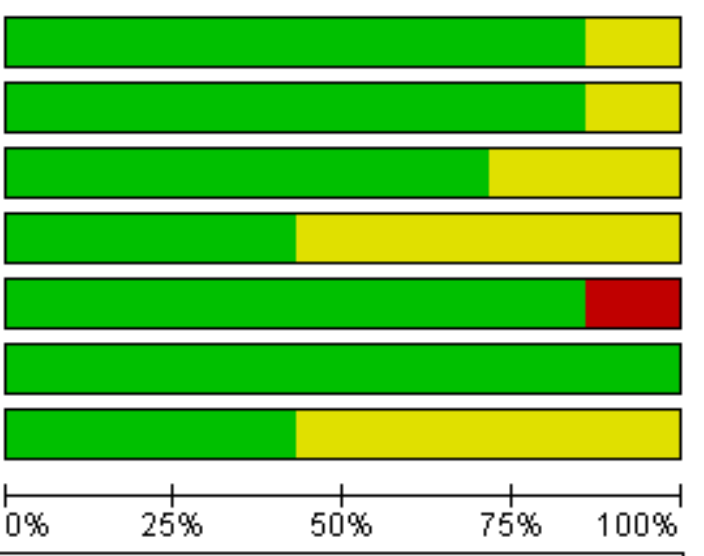


Figure 2

Risk of bias graph

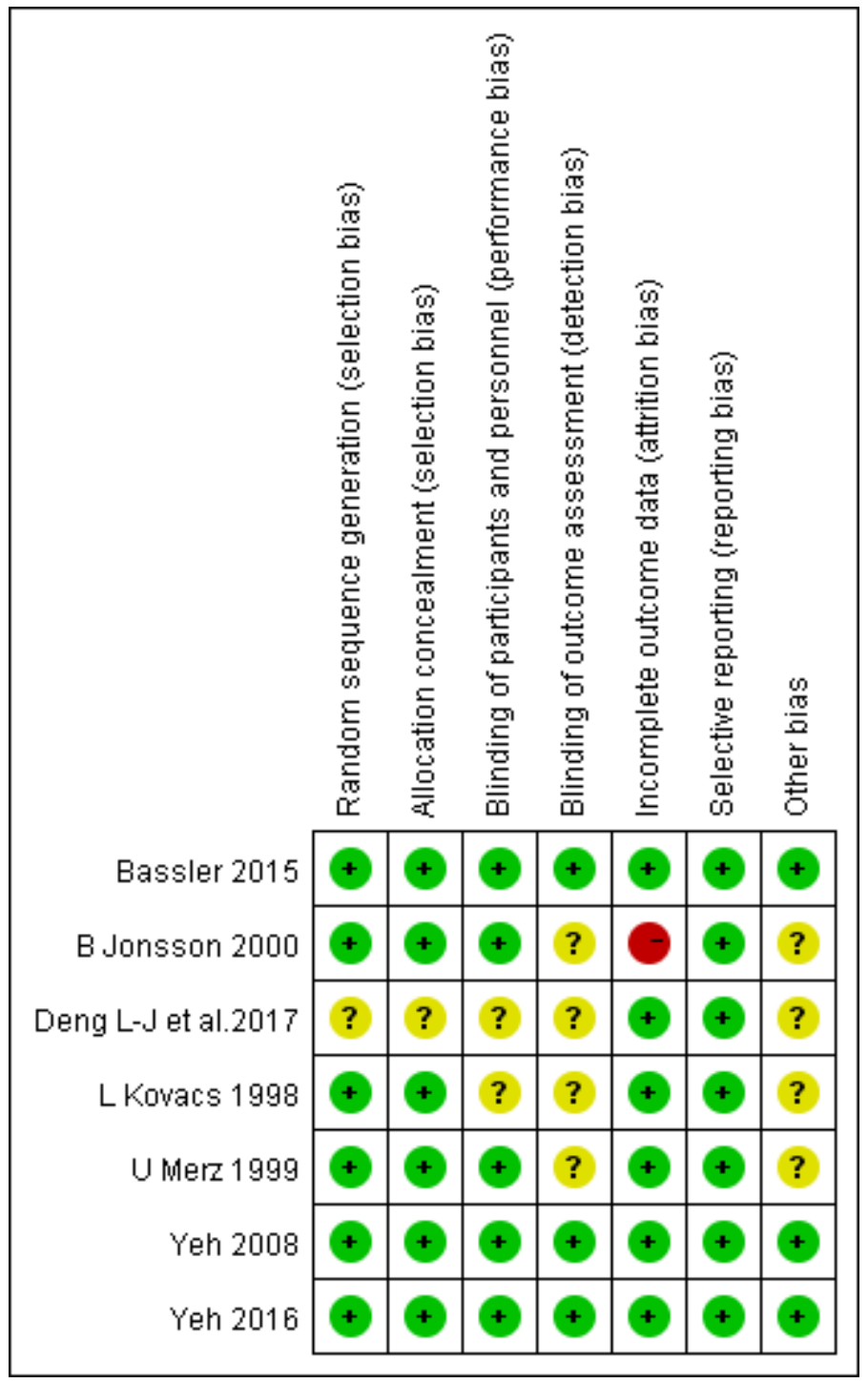

\section{Figure 3}

Risk of bias summary for all included records 
Budesonide Control Risk Ratio

Studv or Subgroup Events Total Events Total Weight M-H, Fixed, 95\% C

\subsubsection{Subgroup 1}

$\begin{array}{lrrrrrr}\text { Bassler 2015 } & 101 & 437 & 138 & 419 & 53.9 \% & 0.70[0.56,0.87] \\ \text { Deng L-J et al.2017 } & 3 & 18 & 17 & 28 & 5.1 \% & 0.27[0.09,0.80] \\ \text { Yeh 2008 } & 9 & 60 & 16 & 56 & 6.3 \% & 0.53[0.25,1.09] \\ \text { Yeh 2016 } & 38 & 131 & 67 & 134 & 25.3 \% & 0.58[0.42,0.80] \\ \text { Subtotal (95\% Cl) } & & \mathbf{6 4 6} & & \mathbf{6 3 7} & \mathbf{9 0 . 6 \%} & \mathbf{0 . 6 3}[0.53, \mathbf{0 . 7 5}] \\ \text { Total events } & 151 & & 238 & & & \end{array}$

Heterogeneity: $\mathrm{Chi}^{2}=3.72, \mathrm{df}=3(\mathrm{P}=0.29) ; \mathrm{I}^{2}=19 \%$

Test for overall effect: $Z=5.22(P<0.00001$ )

\subsubsection{Subgroup 2}

$\begin{array}{lrrrrrr}\text { B Jonsson } 2000 & 8 & 13 & 11 & 14 & 4.0 \% & 0.78[0.47,1.30] \\ \text { L Kovacs } 1998 & 10 & 30 & 14 & 30 & 5.4 \% & 0.71[0.38,1.35] \\ \text { U Merz } 1999 & 0 & 12 & 0 & 11 & & \text { Not estimable } \\ \text { Subtotal }(95 \% \mathrm{Cl}) & & \mathbf{5 5} & & \mathbf{5 5} & \mathbf{9 . 4} \% & \mathbf{0 . 7 4}[\mathbf{0 . 4 9 , \mathbf { 1 . 1 3 } ]} \\ \text { Total events } & 18 & & 25 & & & \end{array}$

Heterogeneity: $\mathrm{Ch}^{2}=0.05, \mathrm{df}=1(\mathrm{P}=0.81) ; \mathrm{I}^{2}=0 \%$

Test for overall effect: $Z=1.38(P=0.17)$

Total $(95 \% \mathrm{Cl})$

Total events 169

701

Heterogeneity: $\mathrm{Ch}^{2}=4.41, \mathrm{df}=5(\mathrm{P}=0.49) ; \mathrm{I}^{2}=0 \%$

Test for overall effect: $Z=5.40$ ( $P<0.00001$ )

Test for subaroun differences: $\mathrm{Ch}^{2}=0.50$. df $=1(\mathrm{P}=0.48) . \mathrm{I}^{2}=0 \%$
Risk Ratio

M-H, Fixed, 95\% Cl

\section{Figure 4}

Budesonide vs control (BPD)

Budesonide

Control

Risk Ratio

Risk Ratio

Studv or Subgroup

Events Total Events Total Weight M-H, Random, 95\% Cl

M-H, Random, 95\% Cl

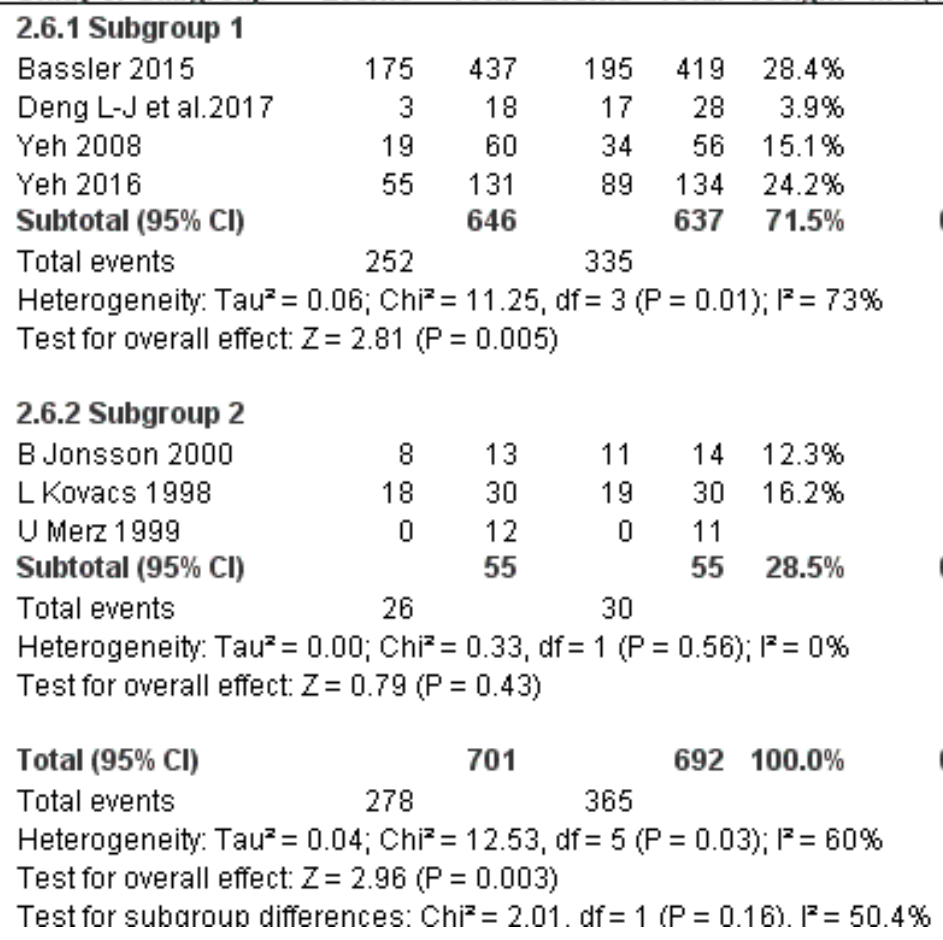

$0.86[0.74,1.00]$

$0.27[0.09,0.80]$

$0.52[0.34,0.80]$

$0.63[0.50,0.80]$

0.64 [0.47, 0.87]

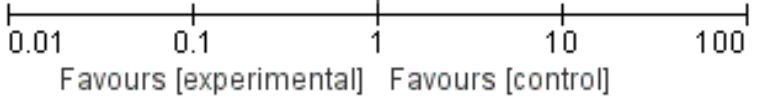

$0.78[0.47,1.30]$

$0.95[0.64,1.41]$

Not estimable

0.88 [0.64, 1.21]

$0.71[0.57,0.89]$

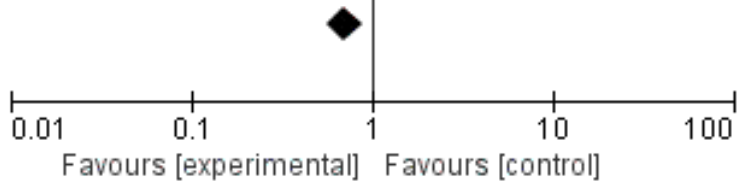

\section{Figure 5}


2.3.1 Subgroup 1

Bassler 2015

Deng L-J et al. 2017

Yeh 2008

Yeh 2016

Subtotal $(95 \% \mathrm{Cl})$

Total events

$\begin{array}{rrrrr}74 & 437 & 57 & 419 & 37.8 \% \\ 0 & 18 & 0 & 28 & \\ 10 & 60 & 18 & 56 & 22.3 \% \\ 17 & 131 & 22 & 134 & 25.9 \% \\ & \mathbf{6 4 6} & & \mathbf{6 3 7} & \mathbf{8 6 . 0} \%\end{array}$

$101 \quad 97$

Heterogeneity: $\operatorname{Tau}^{2}=0.14 ; \mathrm{Chi}^{2}=6.00, \mathrm{df}=2(\mathrm{P}=0.05) ;\left.\right|^{2}=67 \%$

Test for overall effect: $Z=0.59(P=0.55)$

\subsubsection{Subgroup 2}

B Jonsson 2000

L Kovacs 1998

U Merz 1999

Subtotal $(95 \% \mathrm{Cl})$

Total events

Heterogeneity: Not applicable

Test for overall effect: $Z=0.92(P=0.36)$

Total $(95 \% \mathrm{Cl})$

701

$692100.0 \%$

Total events 109 102

Heterogeneity: Tau $^{2}=0.11 ; \mathrm{Chi}^{2}=6.79, \mathrm{df}=3(\mathrm{P}=0.08) ; \mathrm{I}^{2}=56 \%$

Test for overall effect: $Z=0.26(P=0.80)$

Test for subaroun differences: $\mathrm{Ch}^{2}=1.19 . \mathrm{df}=1(\mathrm{P}=0.27) . \mathrm{I}^{2}=16.3 \%$

$1.24[0.91,1.71]$ Not estimable $0.52[0.26,1.03]$ $0.79[0.44,1.42]$ $0.86[0.51,1.44]$

\section{Figure 6}

Budesonide vs Control (Death)

\section{Supplementary Files}

This is a list of supplementary files associated with this preprint. Click to download.

- ForestplotInfectionorSepsis.png

- PRISMAchecklist.doc

- ForestplotROP.png

- Table1.BaselineCharacteristicsofthe7RCTS.xls

- Table2.Detailsofthe7RCTS.xIs

- Table3.BudesonidevsControllnfectionorSepsis.xls

- Table4.BudesonidevsControlIVH.xIs

- Table5.BudesonidevsControlROP.xls

- ForestplotIVH.png 